\title{
Metabolic Syndrome and Cancer: Cause or Consequence?
}

\section{Siviero-Miachon AA ${ }^{1}$, Spinola-Castro AM $^{1}$ and Guerra-Junior $\mathbf{G}^{2 *}$}

${ }^{1}$ Federal University of Sao Paulo - UNIFESP/EPM, Department of Pediatrics, Division of Pediatric Endocrinology, Sao Paulo - SP, Brazil

${ }^{2}$ University of Campinas - UNICAMP, Faculty of Medical Sciences, Department of Pediatrics, Division of Pediatric Endocrinology

Ever since Reaven has described the condition named as the syndrome $\mathrm{X}$ in 1988 [1], which is now known as the metabolic syndrome (MetS), more than 30,000 papers have been published focusing on this important issue. There are important concerns related to MetS comprising the discussion about the definition, causes and some conditions predisposing to the disease. To date, it is quite evident that along with the growing epidemic of obesity and chronic diseases worldwide, metabolic dysfunction leading to increased cardiovascular risk morbidity and mortality are increasing markedly [2-4]. Insulin resistance (IR) and endothelial dysfunction are the probable mechanisms linking all the features of MetS, comprising visceral obesity, glucose intolerance or type 2 diabetes mellitus, arterial hypertension, atherogenic dyslipidemia, proinflammatory and prothrombotic state [1-4].

More recently it has become quite evident the importance of the relationship between obesity and the clustering of other MetS components, especially in the context of cancer development. Thus far, MetS may increase the risk of cancer, whereas, consecutively, cancer may lead to features of MetS [2-6]. The pathophysiological and biological mechanisms underlying the association between MetS and cancer still remain unexplained and are starting to be understood. Nonetheless, it is apparent by epidemiological studies that MetS traits increase the risk of cancer $[5,6]$ and that, sequentially, survivors of various malignancies may present MetS traits several years after cancer therapy withdrawal [2-4].

Carcinogenesis is multifactorial, and depends not only on metabolic disturbances, but also on the inherited genetic background. MetS may be related to cancer via different mechanisms that act in an additive and synergistic manner. Most of the components of MetS in some way have been individually linked to the development of cancer, but few studies have linked the MetS itself to cancer risk [5]. Individual requirements of MetS may contribute to the development of various processes leading to cancer, but they all work together beyond that of the individual components alone. The mechanisms involved in carcinogenesis are increased hormone bioavailability, through insulin and insulin-like growth factor (IGF), resulting in IR, enhanced aromatase activity (and increased sex steroids production), elevated adipokine production and glucose utilization, oxidative stress, DNA damage and consequently promoting an energy-rich environment, cell transformation, migration and proliferation, angiogenesis, as well as inhibition of apoptosis [2,4-6]. Insulin receptor, particularly the isoform $\mathrm{A}$, also plays an important role in this process since it is overexpressed in several human malignancies, binding not only insulin, but also IGF-2. Additionally, insulin receptors contribute to the formation of hybrid receptors with IGF-1 receptors and, by binding to hybrid receptors, insulin stimulates specific signaling pathways related to IGF1 . Thus far, these receptors are the major targets for novel anti-cancer therapies [2,4-6].

Another important aspect concerning this association is that, in the last years, together with the better care committed to patients with cancer, the establishment of chemotherapy (CT) and the advances in radiotherapy (RT), survival rates have greatly improved. Consequently, the number of patients that reach adulthood presenting some late side effects of cancer treatment or mortality due to CVD is increasing continuously [2-4]. Survivors of specific pediatric cancer groups, particularly acute lymphocytic leukemia, brain tumors, sarcomas, lymphomas, disseminated testicular cancer, neuroblastomas, Wilms tumor, and following bone marrow transplantation are recognized to present clinical features of MetS and therefore increased risk factors for CVD [2-4,7-9]. According to a statement developed by the American Heart Association along with the Council for Cardiovascular Disease in the Young, post-cancer treatment survivors are classified as tier III, which means increased cardiovascular disease (CVD), with epidemiological evidence for manifest early in adulthood, but after 30 years of age [10]. The mechanisms behind this are not clarified yet. Nonetheless, the neoplastic disease itself along with therapy (including CT and RT) may probably activate some pathways, different from those in non-cancer populations, underlying mechanisms for weight gain and IR, hormone deficiencies (particularly GH deficiency due to cranial RT-induced hypothalamic damage), changes on lipid metabolism, inflammatory mediators, adipokines, endothelial function, hyperhomocystinemia (secondary to methotrexate therapy) and magnesium deficiency $[2,3]$.

In conclusion, obesity and hyperinsulinemia should be treated by changes in lifestyle and/or pharmacological approaches in order to prevent risks for related cancers. On the other hand, the prevalence and pathogenesis of MetS traits in long-term survivors of cancer, the significance of this syndrome, as well as the relationship between MetS and the development of CVD after cancer treatment are important issues that must be better evaluated and understood. Weight gain, especially in some specific cancer groups predisposing to MetS traits, must encourage a more active lifestyle during the first years of therapy. Overall, the understanding of the complex systems that determine cancer in populations with features of MetS, focusing on anti-cancer and gene therapies, as well as the importance of each individual component of MetS in determining cancer, should be more clearly defined in the near future. Possibly, if we find the best way to prevent MetS in various populations predisposing to metabolic disturbances, we could find the link between these two conditions and prevent cancer development [2-6].

Cancer and MetS: which of these conditions come first? Definitely, this association is a target to pursue.

\section{References}

1. Reaven GM (1994) Syndrome X: 6 years later. J Intern Med 736: 13-22.

2. Siviero-Miachon AA, Spinola-Castro AM, Guerra-Junior G (2008) Detection of

Corresponding author: Guerra-Junior G, University of Campinas - UNICAMP, Faculty of Medical Sciences, Department of Pediatrics, Division of Pediatric Endocrinology, PO Box 6111, Zip Code 13083-970, Campinas - SP, Brazil, Tel: + 5519 3521-7353; Fax: + 5519 3521-7322; E-mail: gilguer@fcm.unicamp.br

Received January 16, 2012; Accepted January 18, 2012; Published January 23, 2012

Citation: Siviero-Miachon AA, Spinola-Castro AM, Guerra-Junior G (2012) Metabolic Syndrome and Cancer: Cause or Consequence? J Metabolic Synd 1:e103. doi:10.4172/2167-0943.1000e103

Copyright: (c) 2012 Siviero-Miachon AA, et al. This is an open-access article distributed under the terms of the Creative Commons Attribution License, which permits unrestricted use, distribution, and reproduction in any medium, provided the original author and source are credited. 
metabolic syndrome features among childhood cancer survivors: a target to prevent disease. Vasc Health Risk Manag 4: 825-836.

3. Spinola-Castro AM, Siviero-Miachon AA, Guerra-Junior G, Geloneze B (2009) Insulin resistance in childhood cancer survivors: a link between metabolic syndrome features. In: E. B. Yao, ed. Insulin resistance: new research. 1 ed. New York: Nova Science Publishers, v 1, p. 235-251.

4. Siviero-Miachon AA, Spinola-Castro AM, Guerra-Junior G (2009) Adiposity in childhood cancer survivors: insights into obesity physiopathology. Arq Bras Endocrinol Metab 53: 190-200.

5. Cowey S, Hardy RW (2006) The metabolic syndrome: A high-risk state for cancer? Am J Pathol 169: 1505-1522.

6. Castro AM, Guerra-Junior G (2005) [GH/IGF-1 and cancer: what's new in this association]. Arq Bras Endocrinol Metabol 49: 833-842.
7. Srinivasan S, Ogle GD, Garnett SP, Briody JN, Lee JW, et al. (2004) Features of the metabolic syndrome after childhood craniopharyngioma. J Clin Endocrino Metab 89: 81-86.

8. Oeffinger KC, Adams-Huet B, Victor RG, Church TS, Snell PG, et al. (2009) Insulin resistance and risk factors for cardiovascular disease in young adult survivors of childhood acute lymphoblastic leukemia. J Clin Oncol 27: 36983704.

9. Van Waas M, Neggers SJ, Pieters R, van den Heuvel-Eibrink MM (2010) Components of the metabolic syndrome in 500 adult long-term survivors of childhood cancer. Ann Oncol 21: 1121-1126.

10. Kavey RE, Allada V, Daniels SR, Hayman LL, McCrindle BW, et al. (2006) Cardiovascular risk reduction in high-risk pediatric patients. Circulation 114 2710-2738. 